\title{
Pancreatoduodenectomy co-morbid with celiac axis compression syndrome: a report of three cases
}

Katsuki Miyazaki, Yuji Morine, Yu Saito, Shinichiro Yamada, Kazunori Tokuda, Tetsuya Ikemoto, Satoru Imura and Mitsuo Shimada*

\begin{abstract}
Background: Celiac axis compression syndrome (CACS) is a relatively rare disease. Because of the nature of the blood flow in the celiac region when a pancreatoduodenectomy (PD) is performed for CACS, the celiac region can become ischemic. The aim of this study is to report on the importance of pre-operative diagnosis of CACS in terms of the outcomes for patients post-operatively. In this study, three 3 cases of PD co-morbid with CACS are reported: one intra-operative diagnosis case and two pre-operative diagnosis cases.

Case presentation: The one case, not diagnosed with CACS prior to the operation, had a hard post-operative course because of complication caused by ischemia of the celiac region compared with the two cases diagnosed prior to the operation, who had a good post-operative course because of pre-operative or intra-operative intervention.

Conclusions: Post-operative complications due to CACS are preventable by pre-operative diagnosis and appropriate interventions.

Keywords: Pancreatoduodenectomy (PD), Celiac axis compression syndrome (CACS), Median arcuate ligament syndrome (MALS), Gastroduodenal artery (GDA)
\end{abstract}

\section{Background}

Celiac axis compression syndrome (CACS) is a relatively rare disease caused by stenosis of the celiac trunk. Various symptoms are associated with CACS such as abdominal pain occurring after meals, weight loss, nausea, vomiting, and diarrhea. The causes of CACS are compression by the median arcuate ligament (55\%) which is the most common cause and known as median arcuate ligament syndrome (MALS), sclerosis (15\%), and others (35\%) [1]. In the case of CACS, the blood flow in the celiac region, including the hepatic artery, is preserved by the flow of the gastroduodenal artery (GDA) from the superior mesenteric artery. So when a pancreatoduodenectomy (PD) with the dissection of GDA is performed,

\footnotetext{
* Correspondence: mitsuo.shimada@tokushima-u.ac.jp

The Department of Digestive and Transplant Surgery, Tokushima University, 3-18-15 Kuramoto-cho, Tokushima City, Tokushima 770-8503, Japan
}

the celiac region can become ischemic. Ischemia of the celiac region causes high mortality complications such as liver failure, liver abscess, and anastomotic dehiscence with subsequent bile leakage [1-4]. It is reported that about 2 to $7.6 \%$ of cases of PD are co-morbid with CACS $[1-3,5]$. Recently, Japanese Society of HepatoBiliary-Pancreatic Surgery obligates board-certified expert surgeons to perform intraoperative GDA clump test in PD. In this study, three cases of PD co-morbid with CACS are reported, and the literature, including the most recent available, is introduced.

\section{Case presentation 1}

This patient presented as a healthy male in his forties. An abdominal computerized tomography $(\mathrm{CT})$ for abdominal bloating and vomiting showed acute pancreatitis and stenosis of the duodenum. Conservative treatment was not

\section{Springer Open}

(c) The Author(s). 2020 Open Access This article is licensed under a Creative Commons Attribution 4.0 International License, which permits use, sharing, adaptation, distribution and reproduction in any medium or format, as long as you give appropriate credit to the original author(s) and the source, provide a link to the Creative Commons licence, and indicate if changes were made. The images or other third party material in this article are included in the article's Creative Commons licence, unless indicated otherwise in a credit line to the material. If material is not included in the article's Creative Commons licence and your intended use is not permitted by statutory regulation or exceeds the permitted use, you will need to obtain permission directly from the copyright holder. To view a copy of this licence, visit http://creativecommons.org/licenses/by/4.0/. 
successful, and he was subsequently introduced to our department, where further investigations were carried out. Blood tests showed a slight elevation of the liver deviation enzyme, but amylase and tumor markers were normal. An upper gastro-intestinal endoscopy detected redness and swelling at the descending part of the duodenum blocking the further passage of fiber. An upper gastro-intestinal examination also showed obstruction of the duodenum. An enhanced CT revealed a low-density mass surrounding the normal tissues of the pancreas and duodenum (Fig. 1a). According to magnetic resonance imaging (MRI), the mass around the pancreas and duodenum was slightly high in the intensity area in the T2-weighted image and high intensity in the diffusion-weighted area. Thus, malignancy could not be contradicted, and a pylorus-preserving pancreaticoduodenectomy (PPPD) was performed. During the operation, in the middle of reconstruction, the hepatic artery was found to be pulseless. The enhanced CT was carefully reviewed, and stenosis of the celiac trunk due to compression by the median arcuate ligament was confirmed (Fig. 1b). A three-dimensional (3D) reconstruction image of blood vessels also showed a dilated and tortuous inferior pancreaticoduodenal artery (Fig. 1c). An intraoperative diagnosis of CACS due to MALS was made. Dividing the connective tissue around the celiac trunk and elevating the patient's blood pressure resulted in the recovery of the hepatic artery pulse. After the operation, vasopressor therapy (target: sBP $140-160 \mathrm{mmHg}$ ) was performed to preserve the blood flow. Prostaglandine E1 (PGE1) was also used as it contributes to dilation of the hepatic artery as well as increasing collateral circulation. In spite of the interventions, multiple liver abscesses occurred and drainage was necessary on several occasions. Drainage and antibiotic therapy were effective in causing the gradual reduction of the abscesses (Fig. 2a, b, c). An enhanced CT undertaken before the operation confirmed the presence of stenosis of the celiac trunk (Fig. 3a). One week after the operation, the roots of the celiac trunk and the proper hepatic artery were not visualized (Fig. 3b). Two months after the operation, following continuing vasopressor therapy and administration of PGE1, blood flow of the hepatic artery was recovered by growing collateral blood flow (Fig. 3c). Splenic arterial flow was good at both pre- and postoperative CT angiography. Furthermore, dorsal pancreatic artery, which was branched from SMA, flowed into the splenic artery (Fig. 3d). Because this collateral flow from dorsal pancreatic artery played important roles, ischemic complications of the stomach did not occur in this case. The patient was discharged from the hospital at 295 post-operative days.

\section{Case presentation 2}

This patient was a female in her seventies who had visited a nearby doctor complaining of anorexia. A blood test showed jaundice, and a CT revealed a pancreas head tumor. An ENBD tube was inserted, and then the result of pancreatic duct brushing cytology was class $\mathrm{V}$. The patient was introduced to our department for an operation on the pancreas head cancer. A pre-operative CT angiography showed stenosis of the celiac trunk (Fig. $4 \mathrm{a})$, and there was a calcification at the root of the celiac trunk. This was diagnosed as CACS because of the arteriosclerosis. Balloon angioplasties were performed twice before the operation, and the improvement of the stenosis was confirmed (Fig. 4b, c). While waiting for the operation, the patient underwent neo-adjuvant chemotherapy using gemcitabine and paclitaxel for four courses. It took 3 months from the initial visit to the operation, but there was no elevation of tumor markers or enlargement of the tumor size. a

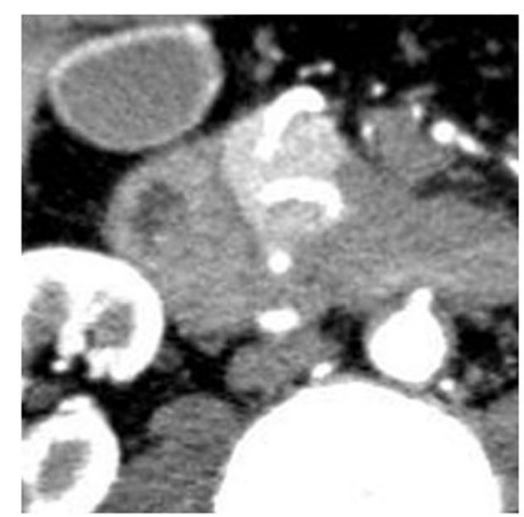

b

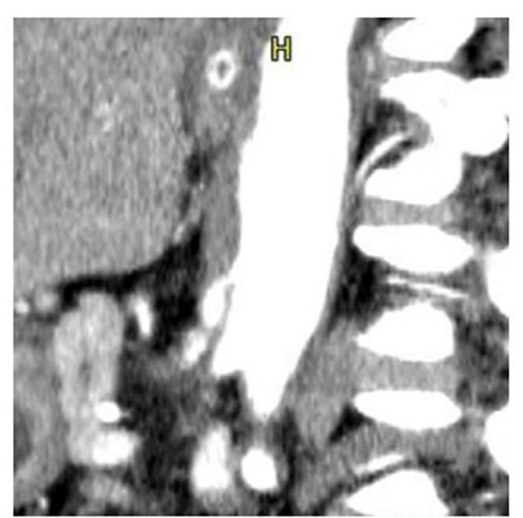

c

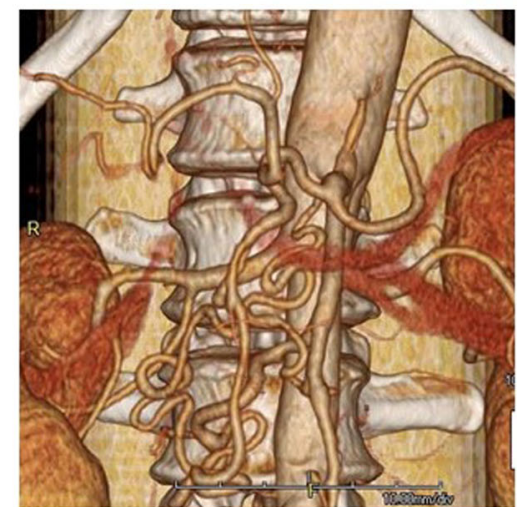

Fig. 1 Preoperative enhanced CT (case 1). a Low-density area surrounding normal tissue of the pancreas and duodenum. b CACS due to MALS. Hooked appearance and minimal post-stenotic dilatation. c 3D reconstruction image of blood vessels. Inferior pancreaticoduodenal artery was dilated and tortuous 


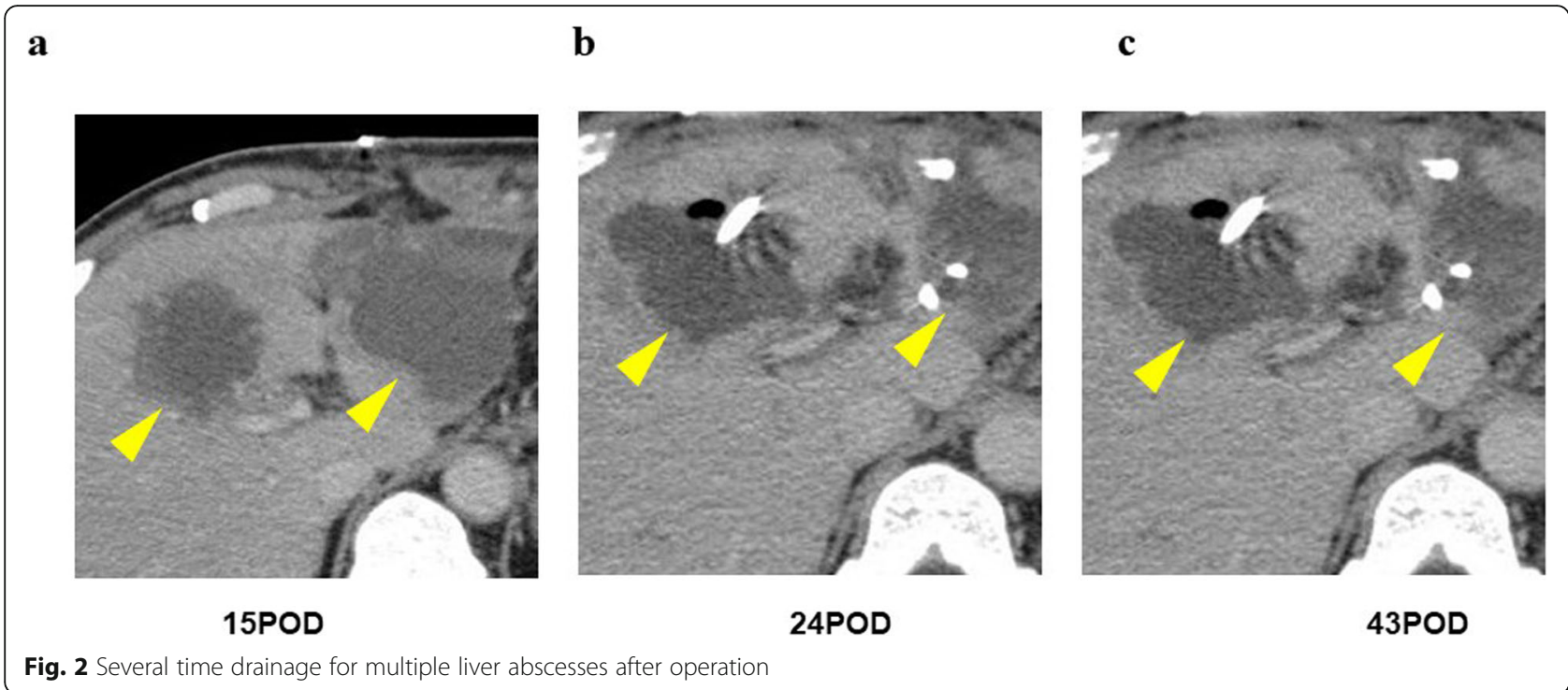

a

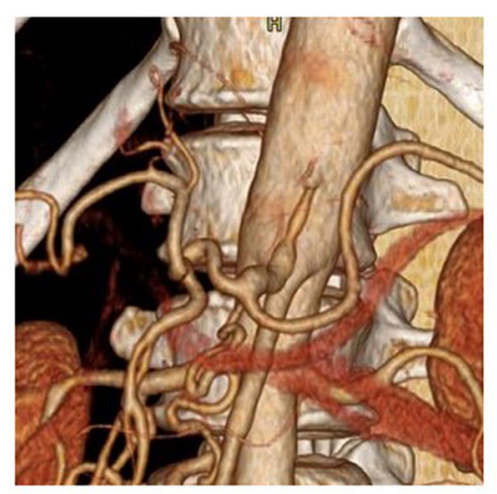

Before operation

b

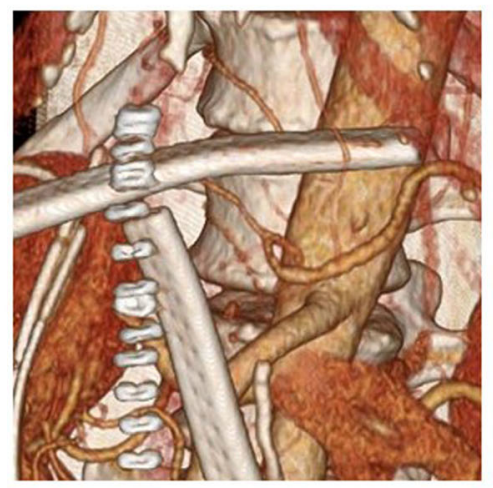

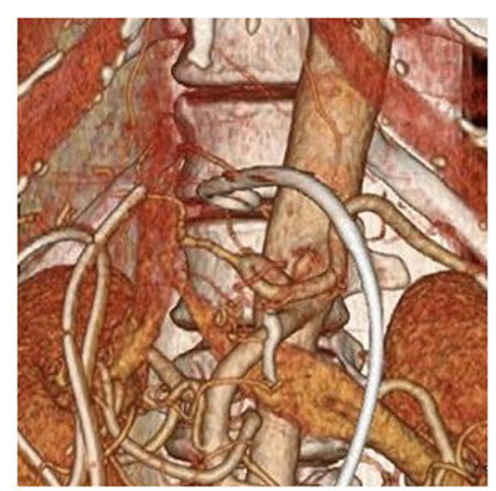

After 2 months

d

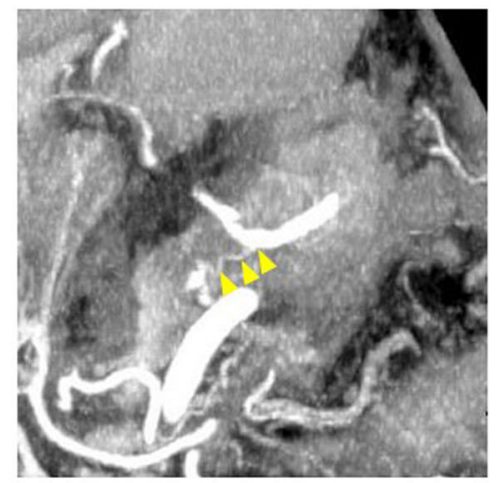

After 1 week

Fig. 3 Time course of 3D CT angiography. a Preoperative $C T$; stenosis of the root of celiac artery. $\mathbf{b} C T$ at 1 week after the operation; absence of the root of celiac artery and the reduction of liver blood flow. $\mathbf{c} C T$ at 2 months after the operation; collateral circulation from dorsal pancreatic artery with recovery of liver blood flow. $\mathbf{d}$ Dorsal pancreatic artery flowed into splenic artery (1 week after the operation) 

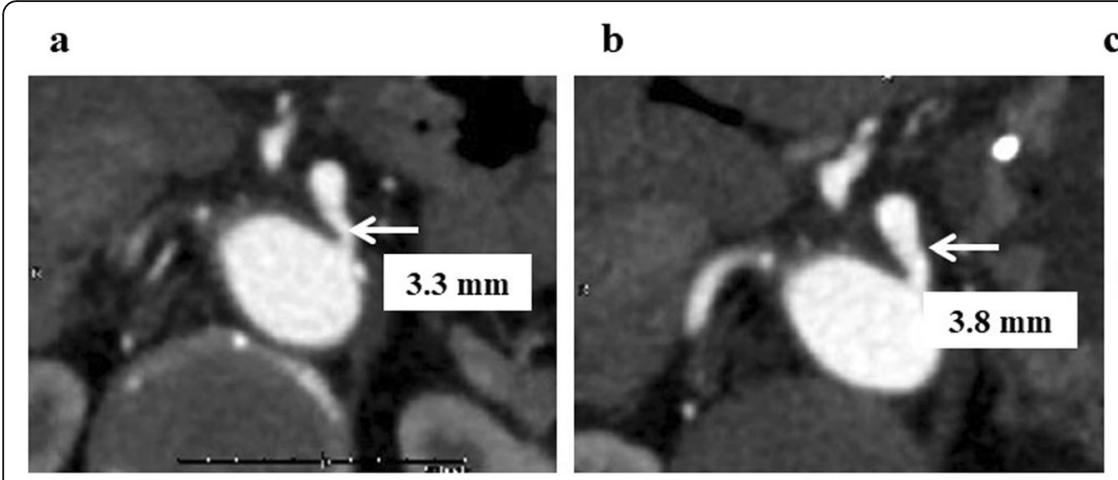

c

Fig. 4 CACS due to sclerosis (case2). Improvement of celiac artery stenosis by balloon angioplasty a $3.3 \mathrm{~mm}$, b $3.8 \mathrm{~mm}$, and c $4.5 \mathrm{~mm}$

A sub-total stomach preserving PD (SSPPD) was performed, and there were no post-operative complications. The patient was discharged from the hospital at 21 postoperative days.

\section{Case presentation 3}

The patient was a female in her fifties who was introduced to our department because of jaundice and stenosis of the inferior bile duct. Pancreatic juice cytology was class IV, so an operation was scheduled for pancreatic head cancer. A pre-operative CT angiography showed stenosis of the celiac trunk because of the compression by the median arcuate ligament and the tortuous nature of the inferior pancreaticoduodenal artery (Fig. 5a, b). MALS was diagnosed pre-operatively, and a SSPPD was performed. During the operation, the median arcuate ligament was released and improvement of the hepatic blood flow confirmed (Fig. 6a, b). Stenosis of the celiac trunk was improved as shown in the postoperative CT angiography (Fig. 7a, b). There were no post-operative complications, and the patient was discharged from the hospital at 15 post-operative days.

\section{Discussion}

Three cases of PD co-morbid with CACS treated at our department were the subject of this study. One case, which could not be diagnosed with CACS before being operated on, had a hard post-operative course because of complication caused by ischemia of the celiac region. Conversely, the two cases, which could be diagnosed as CACS before the operation, had a good post-operative course because of pre-operative or intra-operative intervention.

When the patient is to undergo a planned PD, preoperative diagnosis of CACS is very important. A CT angiography, which has a sensitivity of $96 \%$ and a specificity of $92 \%$, is useful for diagnosing CACS [1]. Specific findings of CACS were already reported: (1) hooked appearance, (2) minimal post-stenotic dilatation as shown in Figs. $1 \mathrm{~b}$ and $5 \mathrm{~b}$, and (3) focal calcified plaque [6]. In both MALS and sclerosis, the clues for diagnosis of CACS at CT angiography are (1) prominent collateral vessels in the pancreatic head, which are originated from SMA, and (2) dilatation of GDA or anterior superior/inferior pancreaticoduodenal artery (ASPDA/AIPDA). Since these characteristic findings of CACS may not be identified on axial a

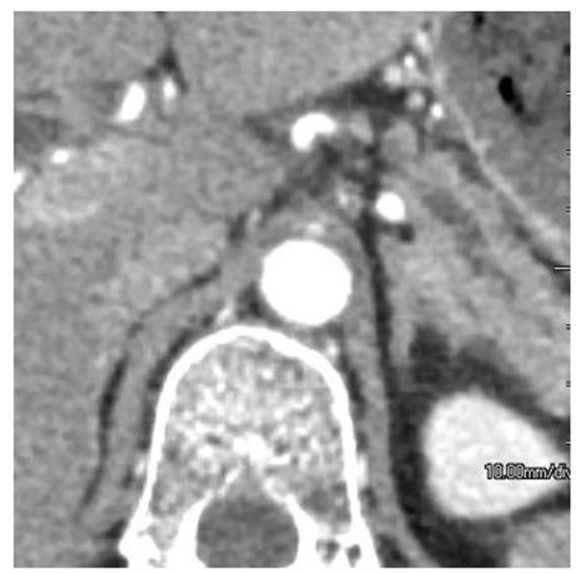

b

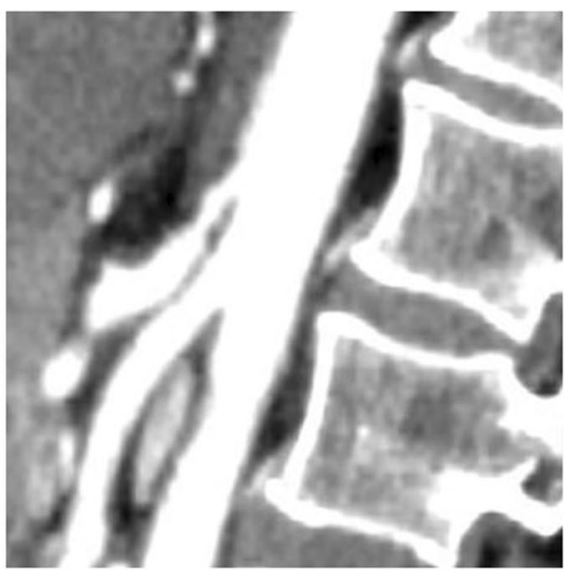

Fig. 5 CACS due to MALS (case 3). Preoperative enhanced CT 
$\mathbf{a}$

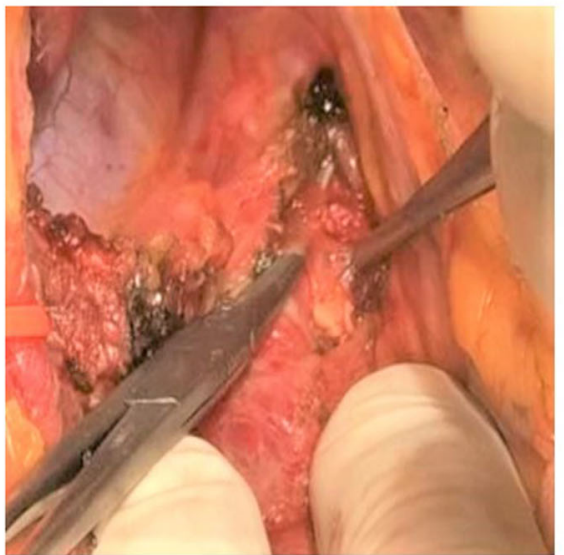

b

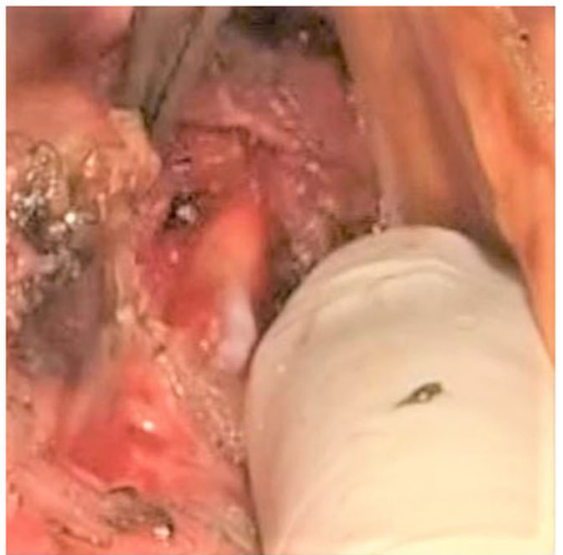

Fig. 6 Operative findings (case 3). MAL division of the root of celiac artery

images alone, 3D imaging also allows identification of CACS. Therefore, the surgeons should carefully check whether there are such collateral vessels or dilated vessels form SMA or not.

The intervention for CACS is different for each case depending on the cause. Table $1[1,3,7,8-16]$ and Table $2[1,3-5,7,17-27]$ show previous reports of PD co-morbid with CACS. The cases featured in Table 1 have CACS because of sclerosis. If the reason for the diagnosis of CACS is sclerosis, there are four treatment strategies: (1) preservation of collateral arteries or GDAs, (2) arterial revascularization, (3) angioplasty by ballooning, and (4) angioplasty by stenting. Conversely, if the reason for CACS is MALS (Table 2), a GDA clamp test should be performed. When the GDA clamp test is negative, no treatment can be considered. At first, when the GDA clamp test is positive, releasing of the median arcuate ligament should be performed. And then, if improvement of the liver blood flow cannot be confirmed, re-vascularization should be considered. Even in the case with very weak palpation of hepatic artery like our case 1 , we should not hesitate to release the median arcuate ligament. It was reported Doppler ultrasonography during GDA clump test is useful $[1,7$, 17]; however, there were no objective criteria for releasing the median arcuate ligament or for additional hepatic arterial reconstruction. In our case 1, ischemic complications of the stomach did not occur fortunately. The indocyanine green fluorescence imaging system (ICG-FS) was reported as a useful devise which can evaluate real-time blood flow of various organs [28]. Intraoperative use of ICG-FS might be recommended for the evaluation of gastric arterial flow. It is also important to evaluate postoperative collateral circulation by CT angiography. As summarized above, Fig. 8 shows the algorithm for diagnosis and treatment of CACS.

\section{$\mathbf{a}$}

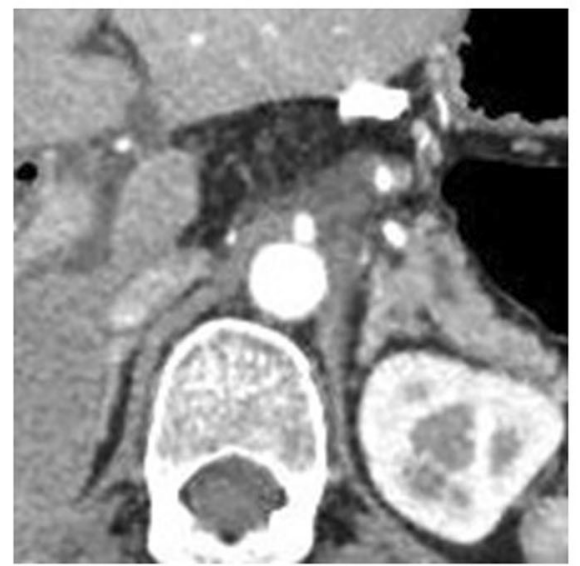

b

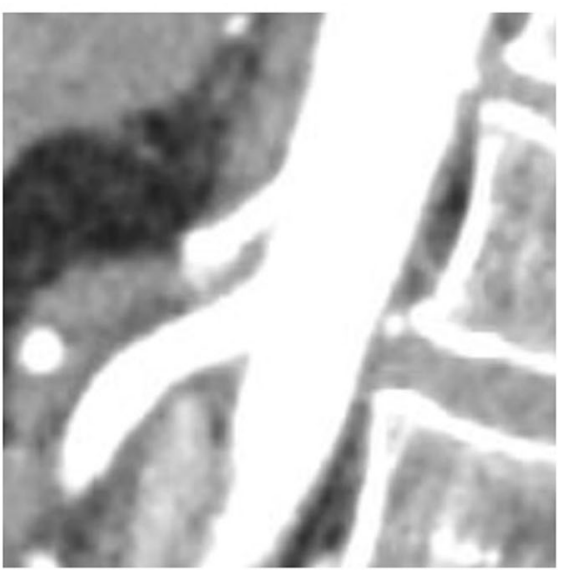

Fig. 7 CT at postoperative day7 (case 3). Disappearance of celiac artery stenosis 
Table 1 Summary of CACS caused by sclerosis on previous literature

\begin{tabular}{|c|c|c|c|c|}
\hline$\overline{\text { Year }}$ & Author & Number & Procedure & Complication \\
\hline 1981 & Thompson & $n=2$ & Splenic_-SMA anastomosis & Uneventful \\
\hline 1988 & Miyata & $n=1$ & Infrarenal Ao- $-\mathrm{CHA}$ bypass & Uneventful \\
\hline 1988 & Noguchi & $n=1$ & PTA & Uneventful \\
\hline 1993 & Chikamori & $n=1$ & GDA_PIPD anastomosis & Uneventful \\
\hline 1995 & li & $n=1$ & Ao-CHA bypass & Uneventful \\
\hline \multirow[t]{2}{*}{1998} & Berney & $n=11$ & $\begin{array}{l}\text { 2: GDA preservation } \\
\text { 2: Ao-CHA bypass } \\
\text { 1: CA reimplantation }\end{array}$ & 1: Pancreatico-jejunal anastomotic leak \\
\hline & & & 5: No treatment & $\begin{array}{l}\text { 2: Liver ischemia } \\
\text { 1: Pancreatico-jejunal anastomotic leak }\end{array}$ \\
\hline 2005 & Kanazaka & $n=1$ & Preservation of collateral arteries & Pseudaneurysm $\rightarrow$ late hemorrhage \\
\hline 2005 & Hayashibe & $n=1$ & Ao-CHA bypass & Uneventful \\
\hline 2005 & Nara & $n=2$ & $\begin{array}{l}\text { 1:MCA—RGEA anastomosis } \\
\text { 1: Preservation of replaced RHA }\end{array}$ & Uneventful \\
\hline 2006 & Halazun & $n=1$ & CA stenting & Uneventful \\
\hline 2009 & Gaujoux & $n=2$ & $\begin{array}{l}\text { 1: CA stenting } \\
\text { 1: Ao—CHA bypass }\end{array}$ & Uneventful \\
\hline 2016 & Sasaki & $n=1$ & Right common iliac artery_CHA bypass & Uneventful \\
\hline
\end{tabular}

Table 2 Summary of CACS caused by MALS on previous literature

\begin{tabular}{|c|c|c|c|c|}
\hline Year & Author & Number & Procedure & Complication \\
\hline 1981 & Fortner & $n=2$ & MAL division & Uneventful \\
\hline 1990 & Kohler & $n=1$ & MAL division & Uneventful \\
\hline 1998 & Okamura & $n=1$ & No treatment & Uneventful \\
\hline 1998 & Berney & $n=2$ & MAL division & Uneventful \\
\hline 2003 & Kawaguchi & $n=1$ & CA saphenous patch & Uneventful \\
\hline 2003 & Hasegawa & $n=1$ & CA stenting & Uneventful \\
\hline 2004 & Kurosaki & $n-3$ & MAL division & Uneventful \\
\hline 2005 & Shima & $n=1$ & JA—GDA anastomosis & Uneventful \\
\hline 2005 & Nara & $n=1$ & MAL division & Uneventful \\
\hline 2007 & Farma & $n=14$ & $\begin{array}{l}\text { 11: MAL division } \\
\text { 1: Ao-CA bypass } \\
\text { 1: Ao-CHA bypass }\end{array}$ & $\begin{array}{l}\text { 1: Liver abscess and biliary anastomotic leak } \\
\text { Uneventful } \\
\text { Uneventful }\end{array}$ \\
\hline 2007 & Nakano & $n=1$ & MAL division & Uneventful \\
\hline 2009 & Gaujoux & $n=55$ & $\begin{array}{l}\text { 32: No treatment } \\
\text { 23: MAL division }\end{array}$ & $\begin{array}{l}\text { 32: Uneventful } \\
\text { 1: CA thrombosis } \\
\text { 1: Stomach ischemia }\end{array}$ \\
\hline 2011 & Saito & $n=1$ & MAL division & Uneventful \\
\hline 2012 & Sugae & $n=12$ & $\begin{array}{l}\text { 1: No treatment } \\
\text { 8: MAL division } \\
\text { 2: IPDA—GDA anastomosis } \\
\text { 1: Preservation of collateral arteries }\end{array}$ & $\begin{array}{l}\text { 1: Ischemic of pancreas tail, spleen, and residual stomach } \\
\text { Uneventful } \\
\text { Uneventful } \\
\text { Uneventful }\end{array}$ \\
\hline 2016 & Park et al. & $n=2$ & $\begin{array}{l}\text { 1: CHA_Ao bypass } \\
\text { 1: CA stenting }\end{array}$ & Uneventful \\
\hline 2018 & Yamamoto & $n=1$ & MAL division & Uneventful \\
\hline
\end{tabular}




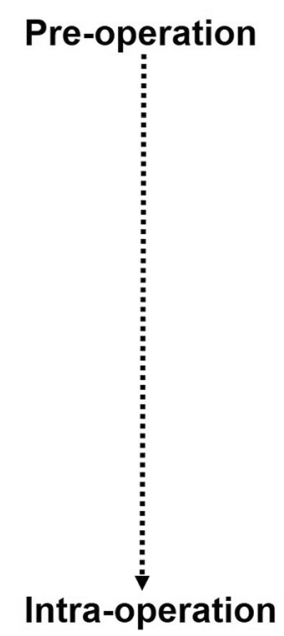

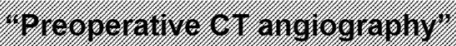

1. Dilated GDA or ASPDA or AIPDA

2. Collateral vessels around pancreas

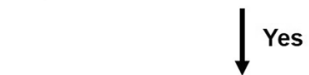

CACS

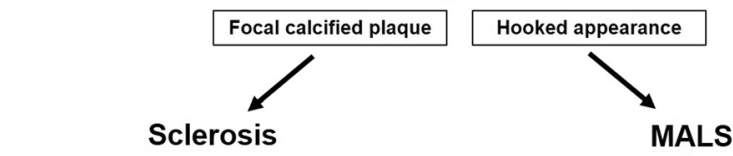

$\downarrow$

Preoperative interventions

Stenting or Ballooning

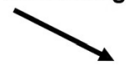

Intoperativ CDA CIIID test

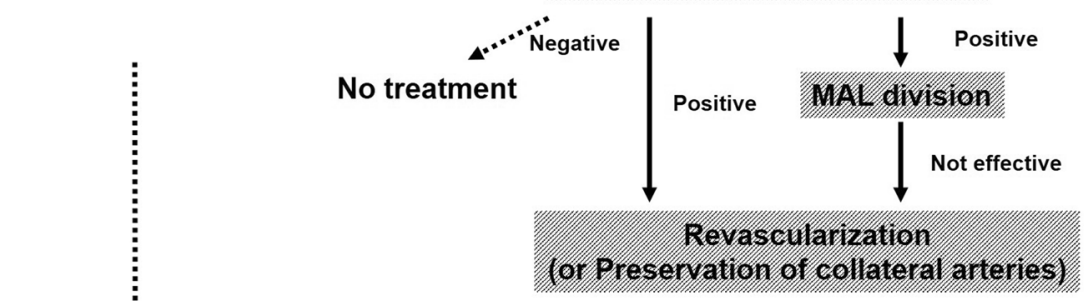

$16 \mathrm{C} \cdot \mathrm{Ps}$

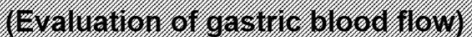

Not enough hepatic blood flow

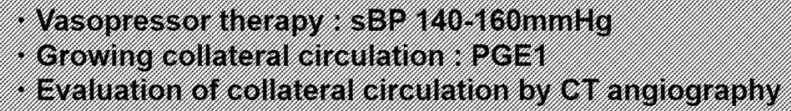

Fig. 8 The algorithm for diagnose and treatment of CACS

As limitation of this report, there were already many case reports of CACS, and its treatment is shown in Tables 1 and 2. In this report, we underwent a case with severe post-operative complications without enough knowledge of CACS. Based on this critical clinical experience, following two cases had good post-operative courses without any postoperative complications by appropriate pre-operative intervention or intra-operative MAL division. In this article, we have summarized three CACS cases in our own facility over the past decade.

\section{Conclusion}

In conclusion, post-operative complications due to CACS are preventable by pre-operative diagnosis and appropriate interventions.

\section{Abbreviations}

CACS: Celiac axis compression syndrome; MALS: Median arcuate ligament syndrome; GDA: Gastroduodenal artery; SMA: Superior mesenteric artery;

PD: Pancreatoduodenectomy; PPPD: Pylorus-preserving PD; SSPPD: Sub-total stomach preserving PD; PGE1: Prostaglandine E1; GDE: Delayed gastric empty; MAL: Median arcuate ligament; ASPDA: Anterior superior pancreaticoduodenal artery; AIPDA: Anterior inferior pancreaticoduodenal artery; ICG-FS: ICG fluorescence imaging system

Acknowledgements

Not applicable.

Authors' contributions

Mitsuo Shimada is the corresponding author and carried out revision of the manuscript. All the authors equally took part in the conception of the case study; acquisition, drafting, and revising of the paper; final approval of the paper; and agreement to be accountable for the integrity of the case report. All authors read and approved the final manuscript.

Authors' information

Not applicable.

Funding

None.

Availability of data and materials

The datasets supporting the conclusions of this article are included within the article and its additional files. 
Ethics approval and consent to participate

Not applicable.

\section{Consent for publication}

All patients provided written informed consents to publish this case report.

\section{Competing interests}

The authors declare that they have no competing interests.

Received: 29 April 2020 Accepted: 17 May 2020

Published online: 24 May 2020

\section{References}

1. Gaujoux S, Sauvanet A, Vullierme MP, Cortes A, Dokmak S, Sibert A, et al. Ischemic complications after pancreaticoduodenectomy: incidence, prevention, and management. Ann Surg. 2009;249:111-7.

2. Miyata T, Yamamoto $Y$, Sugiura T, Okamura $Y$, Ito T, Ashida R, et al. Pancreaticoduodenectomy with hepatic arterial revascularization for pancreatic head cancer with stenosis of the celiac axis due to compression by the median arcuate ligament: a case report. J Surg Case Rep. 2018;1:1-4.

3. Berney $T$, Pretre $R$, Chassot G, Morel P. The role of revascularization in celiac occlusion and pancreatoduodenectomy. Am J Surg. 1998;176(4):352-6.

4. Sugae T, Fujii T, Kodera Y, Kanzaki A, Yamamura K, Yamada S, et al. Classification of the celiac axis stenosis owing to median arcuate ligament compression, based on severity of the stenosis with subsequent proposals for management during pancreatoduodenectomy. Surgery. 2012;151(4): 543-9.

5. Farma JM, Hoffman JP. Nonneoplastic celiac axis occlusion in patients undergoing pancreaticoduodenectomy. Am J Surg. 2007:193(3):341-4.

6. Horton KM, Talamini MA, Fishman EK. Median arcuate ligament syndrome: evaluation with CT angiography. Radiographics. 2005;25(5):1177-82

7. Nara S, Sakamoto Y, Shimada K, Sano T, Kosuge T, Takahashi Y, et al. Arterial reconstruction during pancreatoduodenectomy in patients with celiac axis stenosis—utility of doppler ultrasonography. World J Surg. 2005;29(7):885-9.

8. Thompson NW, Eckhauser FE, Talpos G, Cho KJ. Pancreaticoduodenectomy and celiac occlusive disease. Ann Surg. 1981;193(4):399-406.

9. Miyata M, Takao T, Okuda A, Sasako Y, Sunada S. Pancreatoduodenectomy for periampullary cancer associated with celiac occlusion: a case report. Surgery. 1988;103(2):261-3.

10. Noguchi $Y$, Imada T, Adachi R, Amano T, Kondo J, Matsumoto A, et al. Carcinoma of papilla vater with celiac axis stenosis--application of percutaneous transluminal angioplasty. J J.jpn Surg Soc. 1988;89(5):776-80.

11. Chikamori F, Gunji N, Aoyagi H, Shibuya S, Takase Y, Fukao R. Pancreaticoduodenectomy for carcinoma of the papilla of vater associated with celiac occlusion -a case report and a review of literatures. Jpn J Gastroenterol Surg. 1993;26(5):1286-90.

12. li T, Yasui T, Ito H, Mori K, Kamada T, Akimoto R, et al. A case report of cancer in the head of the pancreas associated with celiac occlusive disease who underwent abdominal aorta-celiac bypass before pancreaticoduodenectomy. Jpn J Gastroenterol Surg. 1995;28(10):2022-6.

13. Kanazawa A, Tanaka H, Hirohashi K, Shuto T, Takemura S, Tanaka S, et al. Pseudoaneurysm of the dorsal pancreatic artery with obstruction of the celiac axis after pancreatoduodenectomy: report of a case. Surg Today. 2005:35(4):332-5.

14. Hayashibe A, Sakamoto K, Shinbo M, Makimoto S, Nakamoto T, Higasiue S, et al. A resected case of advanced duodenal carcinoma with occlusion of the celiac artery. J Surg Oncol. 2005;91(4):270-2.

15. Halazun KJ, Kotru A, Menon KV, Patel J, Parasad KR. Stenting of coeliac axis stenosis facilitates pancreatectomy. Eur J Surg Oncol. 2006;32(7):811-2.

16. Sasaki K, Takahashi T, Kouno S, Wakabayashi M, Fujihira D, Koike T, et al. Pancreaticoduodenectomy and arterial revascularization (right common iliac artery-common hepatic artery bypass) for pancreatic head carcinoma with a stricture of the celiac artery. Jpn J Gastroenterol Surg. 2016;49(3):234-41.

17. Yamamoto M, Itamoto T, Oshita A, Matsugu Y. Celiac axis stenosis due to median arcuate ligament compression in a patient who underwent pancreatoduodenectomy; intraoperative assessment of hepatic arterial flow using doppler ultrasonography: a case report. J Med Case Rep. 2018;12(1):92.

18. Fortner JG, Watson RC. Median arcuate ligament obstruction of celiac axis and pancreatic cancer. Ann Surg. 1981;194(6):698-700.
19. Kohler TR, Debas H, Crames M, Strandness DE Jr. Pancreaticoduodenectomy and the celiac artery compression syndrome. Ann Vasc Surg. 1990;4(1):77-80.

20. Okamura K, Hayakawa H, Kusagawa M, Takahashi H, Kosaka A, Katsuta K, et al. Treatment of pancreas head carcinoma in a 91-yr-old man. Report of a case successfully treated with pylorus-preserving pancreatoduodenectomy. Int J Pancreatol. 1998;24(2):133-8.

21. Kawaguchi K, Seo N, Ohta K, Yasaku Y, Tsuge T, Suzuki K, et al. One exsample which performed of pancreatoduodenectomy as a 2termoperation in the bile duct cancer case complicated with celiac axis obstruction. Jpn J Gastroenterol Surg. 2003;36:272-7.

22. Hasegawa K, Imamura H, Akahane M, Miura Y, Takayama T, Ohtomo K, et al. Endovascular stenting for celiac axis stenosis before pancreaticoduodenectomy. Surgery. 2003;133:440-2.

23. Kurosaki I, Hatakeyama K, Nihei K, Oyamatsu M. Celiac axis stenosis in pancreatoduodenectomy. J Hapatobiliary Pancreat Surg. 2004;11:119-24.

24. Shima $Y$, Yagi $T$, Inagaki $M$, Sadamori $H$, Tanaka $N$, Hiromi $T$, et al. Intraductal oncocytic papillary neoplasm of the pancreas with celiac artery compression syndrome and a jejunal artery aneurysm: report of a case. Surg Today. 2005;35:86-90.

25. Nakano H, Yamamura T, Yamaguchi S, Otsubo T. Celiac axis occlusion of a patient undergoing pancreaticoduodenectomy after distal gastrectomy. Hepatogastroenterology. 2007;54(74):595-8.

26. Saito R, Misawa T, Ito R, Sakamoto T, Shiba H, Yanaga K. Resection of pancreas head carcinoma associated with celiac axis compression by the median arcuate ligament-a case report. J Jpn Surg Assoc. 2011:72(12):3149-53.

27. Park HM, Lee SD, Lee EC, Lee IJ, Han SS, Kim HB, et al. Celiac axis stenosis as a rare but critical condition treated with pancreatoduodenectomy: report of 2 cases. Ann Surg Treat Res. 2016;91(3):149-53.

28. Higashijima J, Shimada M, Yoshikawa K, Miyatani T, Tokunaga T, Nishi M, et al. Usefulness of blood flow evaluation by indocyanine green fluorescence system in laparoscopic anterior resection. J Med Investig. 2019; 66(1.2):65-9.

\section{Publisher's Note}

Springer Nature remains neutral with regard to jurisdictional claims in published maps and institutional affiliations.

\section{Submit your manuscript to a SpringerOpen ${ }^{\odot}$ journal and benefit from:}

- Convenient online submission

- Rigorous peer review

- Open access: articles freely available online

- High visibility within the field

- Retaining the copyright to your article

Submit your next manuscript at $>$ springeropen.com 